\title{
Santo Daime: Teoecologia e adaptação aos tempos modernos
}

\section{Santo Daime: Theo- ecology and adaptation to modern times}

\section{Maria Clara Rebel Araújo*}

Doutoranda pelo Programa de Pós Graduação em Psicologia Social da Universidade do Estado do Rio de Janeiro - UERJ, Rio de Janeiro, RJ, Brasil

\section{Ricardo Vieiralves-Castro**}

Professor Adjunto do Programa de Pós Graduação em Psicologia Social e do Instituto de Psicologia da Universidade do Estado do Rio de Janeiro - UERJ, Rio de Janeiro, RJ, Brasil

\begin{abstract}
Resumo
Este artigo resume os principais aspectos da pesquisa: "Santo Daime: Teoecologia e Adaptação aos tempos modernos", dissertação de mestrado defendida em 2005 pelo PPG-PS/UERJ . O Santo Daime é uma religião que utiliza ritualmente um chá com propriedades psicoativas, acompanhado do canto de hinos que, segundo seus seguidores, tem poder de cura e ensinamentos.Como metodologia, foram realizadas entrevistas semi-dirigidas, bem como uma análise do conteúdo dos hinos mais cantados, a fim de conhecer os aspectos que fazem parte da construção social desta religião na contemporaneidade. Com base nas teorias das Representações Sociais e da Memória Social, procurou-se compreender que tipos de relações psicossociais são construídas dentro da experiência religiosa daimista e também analisar como se deu a interação entre os daimistas amazônicos e os "forasteiros" das grandes cidades que conheceram a doutrina durante as décadas de 70-80 do século passado.
\end{abstract}

Palavras-Chave: Psicologia social, Memória social, Santo Daime, Religiões, Psicoativo.

\begin{abstract}
The present essay summarizes the main contents about the research for the master degree: "Santo Daime: Theo- ecology and adaptation to modern times", concluded in 2005 at the Post-Graduation Program on Social Psychology -UERJ. This doctrine uses in it's rituals a tea with psychoactive properties and also, the singing of a series of anthems, which according to the followers, have power of cure and knowledge. A discourse analysis of the most sung anthems, and semidirected interviews was performed, to aim at knowing Santo Daime's social constructions nowadays better.

The Social Representation Theory and the Social Memory Theory were used to make an analysis of the following issues: to know what kind of psychosociological aspects are built among the Santo Daime's religious experience and
\end{abstract}


understand the expansion of the doctrine to Brazil's biggest cities and abroad which was performed by the Amazon daimists and "foreigners", during the 70's and 80's.

Keywords: Social psychology, Social memory, Santo Daime, Religions, Psychoactive.

\section{I ntrodução}

O presente relato procura resumir os principais aspectos da dissertação "Santo Daime: teoecologia e adaptação aos tempos modernos" defendida em 2005 pelo PPG-PS/UERJ. Nesta pesquisa, procuramos analisar algumas questões psicossociais desta religião amazônica que se espalhou pelo Brasil e o mundo nos últimos 20 anos. Ou seja, procuramos compreender melhor que aspectos sociais, psicológicos e antropológicos estão presentes não só nas raízes do Daime como também como estes foram se elaborando e ganhando complexidade ao longo de sua curta história.

O Santo Daime é uma religião que resgata e valoriza intensamente os estados alterados de consciência (chamados pelos daimistas de mirações) como forma de alcançar a iluminação espiritual, que se realiza não só por meio da ingestão do chá (também conhecido como Daime, yagé, ayahuasca, Vegetal, caapi), mas também pelo canto repetitivo de hinos, que, segundo seus integrantes, são ditados diretamente do mundo Astral, e que contém ensinamentos, poder de cura e revelação. $O$ chá, segundo o fundador da doutrina, Irineu Serra, "tem poder inacreditável", sendo responsável, em alguns casos, por mudanças profundas na visão de si mesmo e do mundo, o que implica em novas posturas e concepções psicossociais.

Um dos objetivos da pesquisa foi investigar como se estabelece a relação hinos-miração, a partir da hipótese de que existiria uma ligação entre a miração e os hinos daimistas, que são sempre cantados quando o chá é tomado. Nossa hipótese foi a de que os hinos dariam um sentido religioso à miração, cambiando-a de um viés estritamente individual para o coletivo. Ou seja, eles integrariam a experiência individual da miração dentro de um todo maior, um sentido religioso. Tal como diz um hino do fundador do Santo Daime, o Mestre Irineu: "Este é o salão dourado/ do nosso Pai verdadeiro/Todos nós somos filhos/Todos nós somos herdeiros". Neste sentido, é pertinente estudar a doutrina do Santo Daime dentro da Psicologia Social, uma vez que esse campo do saber se dedica a entender de forma a relação homem-sociedade num todo dinâmico. No caso desta religião, é difícil isolar os componentes individuais da experiência com o chá do contexto social que o envolve. Não só porque o ritual é complexo e possui, como veremos, uma série de aspectos singulares, como também porque existem mudanças sociais mais amplas que envolvem os adeptos da doutrina. 
Como veremos, existe uma série de construções psicossociais dentro da doutrina daimista, o que a configura como um objeto singular para a compreensão de aspectos importantes da religiosidade contemporânea.

\section{Metodologia e Referências Teóricas}

Nossa pesquisa envolveu um estudo qualitativo sobre a memória pessoal e coletiva de membros do Santo Daime, que são chamados de fardados. Foram realizadas quinze entrevistas semi-dirigidas com roteiro, sendo utilizada uma análise de conteúdo de base qualitativa com classificação temática. Por questões éticas, os entrevistados foram identificados como S2, S3, etc., com exceção dos líderes daimistas Madrinha Julia e Padrinho Alfredo.

Procuramos compreender melhor as mudanças substantivas que permitiram ao Daime o encontro com as camadas médias urbanas, bem como a permanência de tradições que fizeram a doutrina se estruturar de maneira singular. Por isto, optamos por entrevistar os "fardados" mais antigos. Voltamos nosso foco especialmente os que presenciaram ou participaram ativamente da expansão da doutrina para o sudeste, que ocorreu aproximadamente a partir de 1982 e ganhou muita força de 1984 até a década de 90 , continuando nos dias de hoje.

Nossos entrevistados estavam a pelo menos dez anos na doutrina e freqüentando a maioria dos trabalhos espirituais (ou seja, seguindo o calendário ritual daimista) e participando ativamente da mesma. Embora tenham uma visão contemporânea (e mais urbana) do Santo Daime, seus discursos permitem que se vislumbrem os elementos de preservação da memória da doutrina.

As entrevistas foram enriquecidas com a análise dos dois conjuntos de hinos (hinários) mais utilizados pelos adeptos da doutrina, o que nos permitiu entender melhor as correlações entre memória, representações sociais e as práticas sociais do grupo.

O Santo Daime é uma religião que não se assenta puramente no discurso, mas em grande parte na experiência, que vem através da conjugação ritual ingestão do chá-hinos. Os hinos daimistas também mostram fragmentos da memória coletiva da doutrina e também representações sociais, podendo ser considerados fenômenos psicossociais bastante complexos. Tal como ressalta Mauss: "o que vem relacionar esta instituição social, que é a prece, com esta outra instituição social, que é a linguagem" (1979, p. 127-128).

Utilizamos especificamente como bases teóricas a teoria das representações themata tal como este é abordado por Moscovici, ou seja, como ferramenta de análise de discurso, e também outros autores deste campo, como D. Jodelet e Celso Sá. Nossa base teórico-metodológica, 
utilizada no mestrado, foi a análise temática do discurso dos membros do Santo Daime. Portanto, utilizamos os conceitos expostos por Moscovici no texto "O Conceito de Themata"(in: Moscovici 2003), bem como as proposições sobre a construção social da realidade e os conceitos de Memória Coletiva/Social expostos por Le Goff (1984) e Halbwachs (1992), entre outros.

A relação entre hinos e as mirações foi estudada dentro da teoria das representações sociais, uma vez que, como afirmam Jodelet e Sá (in: Sá 2001), uma representação possui uma dupla face, simbólica e figurativa, que visa "tornar o não - familiar-familiar". Sendo formas de saber socialmente partilhadas, os hinos estão repletos tanto de fragmentos da memória coletiva daimista, como também são agentes tanto de reificação do universo consensual como instrumentos de mudanças nesse universo.

Lançamos um olhar em perspectiva sobre a teoria criada por Moscovici e pesquisada por tantos outros por considerá-la séria e ampla o suficiente para abordar um tema tão complexo como a religião e suas relações entre sociedade e indivíduo. Longe de procurarmos tratar o Santo Daime como um caso de patologia social, ou de "válvula de escape para pressões sociais", tal como algumas pesquisas sobre religião sugerem, pretendemos entender as raízes e as dinâmicas individuais e coletivas desta nova vertente religiosa.

Com relação aos daimistas, as entrevistas mostraram que as pessoas (basicamente do Sudeste e Brasília) que conheceram o Daime no Acre na década de 70 se encantaram com a doutrina e o enfoque comunitário criado pelo Pd. Sebastião Mota. Este líder criou uma dissidência daimista denominada Cefluris, com uma forte dinâmica comunitária, que foi a primeira a se expandir para os grandes centros urbanos.

Das pessoas do sudeste que primeiro conheceram e se ligaram ao Santo Daime, havia os que tiveram uma formação marxista, tendo militado em movimentos de esquerda e/ou apoiado presos políticos do regime militar. Essas pessoas não estavam necessariamente buscando uma religião, e muitas eram atéias convictas.

O que parece ter atraído essas pessoas não foi só o chá e seus poderes psicoativos, mas também a possibilidade de uma militância e uma luta política ligada ao desenvolvimento sustentável das comunidades do Acre. Especialmente do Mapiá, vila com características comunitárias criadas por Sebastião Mota e sua família, que lutava pela sobrevivência com muita dificuldade. A luta ecológica pela preservação também foi de importância fundamental, afinal o "povo do daime" sempre esteve intrinsecamente ligado à Amazônia - sendo cada vez mais chamado de Povo da Floresta.

A idéia de ajudar no desenvolvimento de uma comunidade com características tão especiais foi um importante fator de atração e adesão para estes ex-militantes de esquerda, que perceberam que ali havia três causas importantes a serem abraçadas - a preservação da floresta, 
comunidade e da própria doutrina, tal como percebemos no relato que se segue:

\begin{abstract}
E aí o Daime veio para o Sul pela mão destas pessoas que eram pessoas, como o Alex, como o Paulo, tinham 25, 30 anos, pessoas que hoje têm em torno de 50 , todos vindos ou de militância política contra a ditadura, ou antigos hippies, né... Então é uma geração que tinha ido para as drogas, tinha ido para a luta armada, não sei o quê, e tava ali meio querendo uma outra coisa também, eu acho. E chegou o Daime. [...] Uma coisa legal é que a gente sempre tomou com muito respeito, mesmo naquele tempo, né. Sim, todo mundo ateu. (S02- informação verbal)
\end{abstract}

Um tema muito usado pelos entrevistados quando contaram suas memórias biográficas foi a questão da busca, da procura por algo espiritual e com uma religação com a natureza, tal como aponta este trecho de entrevista:

[...] é um caminho de buscadores, de pessoas que querem descobrir algo a mais sobre o caminho espiritual, sobre a sua permanência aqui na Terra, sobre a nossa relação com o Sol, com a Lua, com as Estrelas, com a natureza, então é essa busca interior que faz com que a pessoa se aproxime do Santo Daime. (S10- informação verbal)

A busca religiosa podia ou não estar acompanhada pelo interesse pelo psicoativo. Alguns entrevistados já tinham passado por várias religiões, como o kardecismo, e também as religiões orientais e suas diversas técnicas de meditação e expansão da consciência. Outros buscaram isso através de teorias psicológicas- lembremos que os anos 70 foram palco de um "boom" da psicoterapia, e muitos entrevistados relataram já ter passado pela psicanálise, sendo que um deles é psicólogo com formação em Gestalt. Mas o que foi assinalado por muitos entrevistados é que o Daime seria, digamos, um "acelerador", um "facilitador" do processo de auto-conhecimento. Por exemplo, questões que levariam muito tempo para ser desveladas através de psicoterapia, ou estados mentais que necessitariam de anos de prática meditativa seriam alcançados e trabalhados de forma profunda e mais rápida através do Daime. Tal como afirma S3:

é um instrumento de auto-conhecimento bastante extenso e profundo. E aí é a questão: esse ato de auto-conhecimento é religioso, porque ao mesmo tempo eu não consigo fazê-lo sozinho. Se eu não me irmanar com as Forças Superiores, com as Forças Universais, com as Forças dos Elementos, com Deus representado em tudo isso, eu não vou ter aquela força extra que vai me dar coragem, ou inteligência, ou claridade de pensamento, ou amor, a confiança em si, a confiança em Deus, uma série de coisas que é preciso ter para poder se transcender determinadas 
fronteiras ou barreiras ou véus que existem dentro da gente mesmo. (S3- informação verbal)

A contracultura da década de $60 / 70$ buscava novas formas de se relacionar consigo mesmo e com o outro, menos amarradas aos padrões estabelecidos e convencionais. Alguns entrevistados relataram estar buscando um novo estilo de vida, mais ligado à natureza e a ideais comunitários, estando insatisfeitos com a vida que levavam. Buscavam algo além de ter uma profissão, ganhar dinheiro e consumir os bens da sociedade pós-moderna. Parece haver aqui uma insatisfação quanto aos valores do sistema capitalista e da sociedade ocidental, que no jargão daimista são classificados como "ilusão", "transitoriedade", "coisas do mundo".

\section{Conclusão}

Concluímos então que há um estreito vínculo entre os hinos e a experiência da miração, uma vez que esta não é apenas uma experiência estritamente individual, mas também uma experiência coletiva, unindo os daimistas numa "corrente",e dando-Ihe sentido. Este sentido se faz de forma ampla e não linear, pois ao mesmo tempo que: "O meu encontro com Jesus/ Só eu sei destrinchar", "Ela mostra a todos a todos nós/ Aqui dentro desta verdade". Ou seja, há um fluxo intenso entre o pessoal e o coletivo: "Todos nós somos filhos/Todos nós somos herdeiros". 1 .

Além disso, essa experiência singular proporcionada pelo ritual e pela união entre hinos e miração extravasa para os demais aspectos da vida dos adeptos. Muitas decisões, comportamentos, bem como maneiras de encarar a si mesmo e o mundo são resignificados dentro de uma ótica mais espiritualizada, e há uma ênfase no fato de que os ensinamentos, imagens, e insights do plano espiritual devem se traduzir em práticas sociais: amar e respeitar os irmãos, "esquecer a ilusão", e assim por diante.

Mesmo com todo o seu ecletismo, o Santo Daime é uma religião extremamente singular. Ela reúne um conhecimento antigo, cujas raízes remontam a um passado ameríndio, mas ao mesmo tempo é profundamente brasileira, com seus elementos brancos, negros e caboclos. Além disso, está afinado com o discurso ecológico, enfatizando que a preservação da Amazônia (e da natureza em geral) deve vir acompanhada do bem estar e sustento consciente do povo que vive na natureza.

Gostaríamos de lembrar aqui que para os daimistas os hinos só revelam seu pleno significado e força quando cantados no ritual, acompanhados do chá. Realmente, através de nossa observação pudemos perceber o quanto esse momento é único e especial. Temos a consciência que a análise da 
doutrina apresentada em nossa pesquisa é uma visão acadêmica da mesma, dentro de um ponto de vista psicossocial. Os mistérios e poderes encerrados nos hinos e na experiência do ritual estão guardados para os buscadores, aqueles que se dispuserem a tomar o Daime e ouvir os hinos com algo além da mente racional.

\section{Referências Bibliográficas}

ARAÚjO, M.C.R. Santo Daime: Teoecologia e adaptação aos tempos modernos. 2005. 172 f. Dissertação (Mestrado em Psicologia) - Instituto de Psicologia, Universidade do Estado do Rio de Janeiro, Rio de Janeiro. HALBWACHS, M. A Memória Coletiva. São Paulo: Vértice, 1992.

JODELET, D. Representações sociais: um domínio em expansão. In: $\overline{1} \overline{7}-\overline{4} \overline{4}$.

As Representações Sociais. Rio de Janeiro: EdUERJ, 2001.p.

LABATE, B. C. A literatura brasileira sobre as religiões ayahuasqueiras. In: LABATE, B.C.; ARAÚJO, W.S. (Orgs.). 0 uso ritual da ayahuasca.Campinas: Mercado das Letras, 2004. p. 231-273.

LE GOFF, J. Memória. In: Enciclopédia Einaud. Memória e História. Lisboa: Imprensa Nacional-Casa da Moeda S.A., 1984. p. 11-50.

FLORESTAN, F.; OLIVEIRA, R.C. (org.). Mauss. Antropologia. São Paulo: Ática, 1979.

MOSCOVICl, S. O Conceito de Themata. In: Representações Sociais: Explorações em Psicologia Social. Petrópolis: Vozes, 2003. p. 215-250.

SOARES, L.E. O Santo Daime no contexto da nova consciência religiosa. In: O rigor da indisciplina. Ensaios de antropologia interpretativa. Rio de Janeiro: Iser; Relume-Dumará, 1994. p. 189-222.

\section{Outros tipos de fonte:}

HINÁRI O O CRUZEI RO- MESTRE IRINEU

HINÁRIO O JUSTICEIRO E NOVA JERUSALÉM - PAD. SEBASTIÃO MOTA DE MELO

\section{Páginas da web:}

www. neip.info

www. santodaime.org

\section{Endereço para correspondência}

Maria Clara Rebel Araújo

Universidade do Estado do Rio de Janeiro - UERJ, Instituto de Psicologia, Programa de Pós-Graduação em Psicologia Social, Rua São Francisco Xavier, 524, Bloco F, 10 andar, CEP: 20550-013, Rio de Janeiro, RJ, Brasil.

Endereço eletrônico: clararebel@yahoo.com.br 
Ricardo Vieiralves de Castro

Universidade do Estado do Rio de Janeiro - UERJ, Instituto de Psicologia, Programa de Pós-Graduação em Psicologia Social, Rua São Francisco Xavier, 524, Bloco F, 10ํandar, CEP: 20550-013, Rio de Janeiro, RJ, Brasil.

Endereço eletrônico: ricardo.vieiralves@gmail.com

Recebido em: 02/10/2008

Aceito para publicação em: 16/10/2008

Editor responsável: Ariane Patrícia Ewald

\section{Notas}

* Mestre pelo Programa de Pós Graduação em Psicologia Social da Universidade do Estado do Rio de Janeiro (2005), pesquisadora do Núcleo de Estudos Interdisciplinares sobre Psicoativos

** Doutor pela ECO-Universidade Federal do Rio de Janeiro- UFRJ

1 Trechos dos hinos 93- Padrinho Sebastião e 119 e 124 Mestre Irineu. 